\title{
Buildings, Faces, Songs of Alienation: \\ How Interiority Transforms the Meaning Out There
}

Pieter Marthinus De Kock

University of Lincoln

United Kingdom

\begin{abstract}
This paper presents a theoretical framework that explores visual meaning in the design and use of interior space. It is comprised of three main parts. The first outlines the framework and draws on several key theories. The second introduces three very different constructs as case studies that influence (or are a product of) spatial quality, namely: buildings, faces, and songs of alienation. The third part is a discussion about how each of these three constructs are linked to each other as well as to the idea of interiority. While architectural forms are containers of meaning, the way in which interior space is curated is driven by deeper meaning-one that transcends form and function because people ultimately produce the meaning. And because each person is different, the conditions of interiority (in this case, the meaning that resides within each person) drives the meaning of external constructs that act as enclosures of meaning (buildings and their interiors). The findings are that the mind and body can be projected beyond the facade and into the spaces contained in the buildings we occupy. The role of technology is also important because changes in technology help mediate the process of linking the meaning inside with the meaning out there.
\end{abstract}

Keywords: faces, urban, knowing, machines, lyrics

Correspondence Address: Pieter Marthinus De Kock, School of Architecture and the Built Environment, College of Arts, University of Lincoln, Lincoln LN6 7TS, United Kingdom. Email: PDeKock@lincoln.ac.uk 


\section{Connectivity in Interiority}

For many, a "building is a little song" (Ballantyne, 2007, p. 60) in our hearts with which we orient ourselves. It may be said that we understand the concept of interiority because we understand how a building can exist as a little song within us. And in the daily collection of songs, we experience emergence as an assemblage of feelings drawn from external reality by the process of tacit knowing. We "rely on clues within our bodies to reach beyond ourselves, to attend to what is out there" (Grene, in Polanyi \& Grene, 1969, p. xvi).

For others, there is a different fascination. Andy Warhol's I Want to Be A Machine (Otty, 2005) reflects a preoccupation with alienation and insecurity. This new aesthetic of uncertainty (Columbia GSAPP, 2018a) exposes old lyrics to new meanings and reflects a more general trend of alienation in the urban (Salingaros \& Mehaffy, 2006; Brussat, 2018). Information is generated by surrounding surfaces. If the information we seek is not there, or we "cannot connect to surrounding surfaces, then we find ourselves in an alien environment, and our most basic instincts drive us to leave it" (Salingaros, 1999, p. 29).

Just as faces attract or alienate in split-seconds, so too the inanimate world, through the gaze of buildings and technology. The unfamiliar is attractive, like a magnet, drawing us into a world beyond our comprehension, through the production of increasingly complicated assemblages of unknown constructs generated by Big Data and Artificial Intelligence (AI). Songs help us make sense of that alienation; of what we no longer understand.

The question by Lefebvre (2011), whether we can "be expected to recognise [ourselves] in space merely because that space is held up before [us] like a mirror?" (p. 417) resonates with recent trends concerning the growing levels of human alienation in our urban. "The massive shift from depth to surface that Warhol explained with celebrity culture and advertising has now taken hold of language itself" (Aranda, Wood, \& Vidokle, 2015, p. 9). A trend in language that Stafford (2014) refers to as the "narcissism in public communication" (1:07:00). This public communication includes architecture and buildings. Some would say we should be encouraged to look more attentively (Stafford, 2014, 1:04:00) at artifacts. So that the meaning in a building "stops you and forces you to attend" (Stafford, 2014, 1:10:00).

The theoretical framework, therefore, is as follows. There is a problem of alienation in society, and this paper supports the idea that, through the act of interiorising meaning, interiority can be used to 
combat alienation. How, both as physical and as abstract concepts, the'inside' can become more important than the'outside.'This paper seeks to do so by understanding three constructs: buildings, faces and songs of alienation.

We all inhabit space in comfort or, as often is the case, by degrees of alienation. Alienation is a curious and dangerous phenomenon in our urban, reaching beyond physical constructs. It is all about meaning; in how "... we endow a thing with meaning by interiorizing it and destroy its meaning by alienating it" (Polanyi \& Grene, 1969, pp. 146-147).

In this paper, two streams of thought run simultaneously throughout the document. Firstly, the epistemically objective side of the argument is obvious: that interior spaces in buildings provide the meaning to a building in a physical sense. Without its interior, the building is a meaningless, empty shell. Secondly, as an ontologically subjective analysis: that interiority refers to the analogy being made between our experience as human beings and how we intuitively understand the interiority of spaces in buildings.

\section{Three Conditions of Interiority}

Buildings, faces, and songs of alienation can be introduced in this study by way of a theoretical hypothesis of the relationship that exists between them. Buildings are our inanimate creation. Faces are a creation; with life. And songs are an abstraction; simultaneously something we create and a creation. Lifeless, yet also with a life of its own. Songs, like many other subjective conditions or abstractions, can describe both building and face. Yet neither of these can describe a song.

All three, however, have the capacity to alienate. A building through design, a face in the smallest tacit expression imaginable, and a song through its music and lyrics. All three constructs are imbued with interiority: the building in everything but the external skin; the face implicating the human soul through 'heart' and brain; and the interiority of the song lies in its storytelling, in individuation and the unconscious world of dream and fantasy.

Buildings are what we create, and what we create makes us (Berleant, 1997). Faces are who we are. Songs are gatekeepers for both; guardians of our sanity. A lighthouse separating concrete and abstract, speaking to the things we do not have a language for. Based on this theoretical hypothesis, this study will look at each of these three constructs in turn, starting with buildings. 


\section{Buildings as Containers of Meaning}

Buildings are technologies that "locate interactions" (Guggenheim, in Farias \& Bender, 2010, p. 164): interactions during construction; interactions after the builders have left site; and interactions through change of use as a "Gestalt switch" (Guggenheim, in Farias \& Bender, 2010, p. 167). These interactions all produce knowledge (Piaget, in Peterson, 2017c, 0:53:40). For each building, it can be argued, the most meaningful interactions take place inside.

Visual meaning is based on interaction, and not on a subject or object in isolation of its surroundings. In the traditional sense of building things, it is in the interaction that storytelling exists. It can be argued that buildings must fulfil their role in cities for interaction to take place, not turn their backs on us.

There is also another kind of interaction that takes place; in the duality between interior and exterior. This interaction occurs when reconciling the idea of buildings with faces. Observing people's faces, according to Peterson, provides clues about people's intentions. In other words, a face reveals what is on the 'inside.' But like a facade, it can also deceive.

\section{Our surroundings today represent}

the same circuits that were used when we were out in the forest, or even in the trees, the same circuits we used to parse up the world then, into safe territories. And the place where predators loom, is the way we parse up the world now ... it's become abstracted ... but it's still the same circuit. (Peterson, 2017b, 2:08:05)

Buildings delineate inside from outside. On a more abstract level, however, the 'inside' of buildings can be portrayed as the forest we seek refuge in, away from the exposed open plains. Compounding this sense of creeping alienation is the advent of what can be called the 'digital forest,' and it is in this abstraction where the greatest threat arguably lies, because we have no control over the virtual world. In this world, interactions are created in an instant and disappear in an instant. And there is often nowhere to hide.

How then do we go about properly identifying these physical and mental threats? One could argue that buildings that appear to be aloof or non-communicative are a threat to our mental health, especially when grouped together. This is equally true of the interiors of buildings because if we seek refuge and there is none, then the sense of alienation is complete. 
The failure to stem the sense of alienation lies in the inability of society to address the "invisible crowds of needs" (Lefebvre \& Nicholson-Smith, 2011, p. 394). Others would argue that the threat lies, not in the virtual interactions (the software), but in the technology (the hardware) hidden within the buildings. In buildings where an exterior facade masks big data, algorithms, software, and hardware (Twenty Years Later, 2018) one could ask whether it is an illusion that big data somehow puts the individual in control (Movers and Shakers, 2018), when in fact, our internal feelings point to the contrary.

The sense then is that interiors are not only bound to the physical world through their outer skin but that their abstraction cannot be divorced from the meaning of the surrounding interaction (or lack of interaction). Buildings in a physical sense then are markers of interiority. In another sense, buildings are the faces we look at. And just like our faces hide our inner being, the facade of a building hides its interior. Faces then act as containers of meaning.

\section{Faces as Containers of Meaning}

Faces, in a way, also locate interactions. The face tells us what someone else is up to (Peterson, 2017a, 2017c). "We continually hunt for faces or face-like objects and visually and psychologically attach to them without effort" (Sussman \& Hollander, 2018). This behaviour is arguably about looking to our urban for signals, to orient, to correct signs of 'error' that, like our neurons, light up the interiority; in our internal intuitive world.

Faces, therefore, help us to discern surrounding activity. Anita Say Chan asks the question: "How did the internet come to know you"? (Columbia GSAPP, 2018a). The internet sees us. It has eyes that follow us (Your City is Watching You, 2018). It is the closest we have come to describing our interaction with the digital in terms of a face. The face is a map of a new world which has been adapted, especially for each of us as we move from point $A$ to point $B$ in time and space. A world in which we exist in filter bubbles (Columbia GSAPP, 2018a). The question must be asked eventually: will all we see in the future be avatars of ourselves? Is interiority that provides meaning beyond ourselves (as described by Polanyi \& Grene, 1969) capable of becoming irrelevant?

Faces also appear to us through the built environment in negative ways. Often, for example, in thematic developments by way of the simulacrum, such as Disney World or in many residential projects. 
"Once we recognise the motives and interests that underlie the theme park, can we ever again find satisfaction in its joyful surfaces?" (Berleant, 1997, p. 55). The question we can ask ourselves is: How much of our built environment has become the spectacle that Disney World or themed residential developments represent? The theme itself represents a form of interior or closed off meaning. There is then as much alienation in false information as Berleant (1997) points out, as there is in no information (Salingaros, 1999).

In buildings, the facade is the face; often accentuating the "relationship between readable and non-readable, between what appears and what remains hidden" (Lefebvre \& Nicholson-Smith, 2011 , p. 282). Traditionally the facade reflected the interior of the building, but with Modernism, the facade broke free (Lefebvre \& Nicholson-Smith, 2011) and represented whatever it was ordained to represent by the designer and owner. Thus, the exterior was split off from the interior, both physically and symbolically. Often, we cannot determine from the facade what the contents of the building are. This produces in us a sense of alienation. Because of this fragmentation of meaning, we find it difficult to extend beyond the parts referred to by Polanyi \& Grene (1969), to the meaning out there; of the whole.

Biometrics tell us that people like to look at other people most, which certainly qualifies as what we already know intuitively. We look at people because people's faces are the kind of detail that is most interesting to the brain. So, our experience of places and individual buildings are more pleasing when the places have more people in them and when the buildings have details that suggest the human face or simply more detail rather than less detail (Brussat, 2017).

We continuously scan our urban for levels of cooperation or threat. The visual saliency (Koch, 2013) of faces is implied in a two-way conversation described by Peterson (2017c) that speaks to how we expect our urban to respond to us.

This concept of faces has even been extended to software developed to "perform facial recognition on buildings ... architectural biometrics" (I Run "Facial Recognition", 2018). One interesting observation relates to how older buildings were constructed. That "... evidence called into question previous assumptions that buildings, like a sculpture or a painting, are primarily influenced by just one person" (I Run "Facial Recognition", 2018); when in fact buildings are influenced by many. The point is that the discussion 
is not about technology per se. Technology has, in this example, helped us rediscover our relationship with buildings and faces. How through tacit knowing, through concepts of faces and songs, we are able to understand how to look for the meaning that neutralises levels of alienation.

The fact that buildings are the product of many people, each contributing in unique ways, talks to the concept of interiority; in how incredibly diverse the processes around the traditional building were. Do we, for example not see delightful idiosyncrasies in older buildings precisely because we tacitly recognise the interventions of many individuals, not a single individual? In which a process endures, of slowly enriching meaning during and after construction.

Faces are unique, and this uniqueness is one of the most powerful and enduring influences on our visual perception. It is no wonder therefore that we search for faces in our surrounding built environment. If buildings and faces are containers of meaning, then songs contain those feelings that have no language because there is no language to describe the full meaning of a sense of alienation in the built environment.

\section{Songs as Containers of Alienation}

Songs locate the meaning of interactions or, in the case of alienation, the lack of interaction. The following five songs point to this notion of increasing alienation in the urban.

\section{Song 1}

The first song in this study links up with buildings, which through technology and data, are increasingly acknowledged as machines for living in. We are still fascinated by the possibilities introduced by Le Corbusier. For example, in Andy Warhol's I Want to Be A Machine (Otty, 2005), we dare the machine to occupy us.

Wild thing, I think I love you

But I wanna know for sure

Come on and hold me tight

(Wild Thing, The Troggs, 2019).

The new meaning is unintentional, yet captures our fascination with the data of technology, The concept of objectification in relationships (Carey, 1969) has well and truly transferred itself into our urban. 
In the built environment we can ask ourselves: Do we look at the faces of buildings, so that we can discover the contents? To determine what within is looking back? If the facade is disconnected from meaning, then nothing is looking back at us. But if we focus on the contents of the building, on the inside, then we will discover how technology has reversed the order of the urban. That buildings now gaze back on us; watching our every move. "And if thou gaze long into an abyss, the abyss will also gaze into thee" (Beyond Good and Evil, by Friedrich Nietzsche, 2009). This initial attraction proves to be our undoing, and songs 2 to 5 help us understand the descent into a world of alienation.

Song 2

The second song hints at faces staring back at us.

So I wait in line, I'm a modern man

And the people behind me, they can't understand

Makes me feel like

Something don't feel right

(Modern Man, Arcade Fire, 2019).

The abyss, in many ways, represents our external and internal built environment. The built environment is, after all, the most enduring evidence of our existence. So when "the reciprocity is broken" (Rodaway, 2011, p. 161) and we no longer see and acknowledge being seen, but instead become the object of an indiscriminate gaze, then the building has indeed started looking back at us.

\section{Song 3}

The embodiment it can be argued of a song of alienation is contained in the third song, as streets get rearranged while we are not paying attention.

This town's so strange

They built it to change

And while we sleep we know the streets get rearranged

(Suburban War, Arcade Fire, 2019).

The notions not only of intervention but also of looking back at a past, implied in the third song, are contained in Heidegger's foreshadowing of the rise of technology (Sharr, 2007) as well as a premonition of the shadow (Jung, 2015, 0:46:50). If people succumb to their shadow, then we should expect the unexpected. A city that looks back implies perhaps the futuristic angst projected back on to the living. 
Song 4

In the fourth song, the sense of alienation is complete.

I'm living in an age

Whose name I don't know

(My Body Is A Cage, Arcade Fire, 2019).

In an environment where there are: "Lots of windows and doors, yet [is] blind. As it does not look at the visitor, so it does not expect the visitor's look" (Lyotard, in Leach, 1997, p. 271). Buildings appear not to look at us during the day by way of their visually impenetrable glass facades. At night, however, they epitomise alienation. When we look at them, we see nothing, but illuminated empty stacked floors littered with remnants of the day's workforce.

Current research into the biometric analysis of urban form is at the forefront of understanding what it is that looks back at us (Sussman $\&$ Ward, 2016; 2017; The Neuroscience of Architecture, 2018):

People don't tend to look at big blank things, or featureless facades, or architecture with four-sides of repetitive glass. Our brains, the work of 3.6 billion years of evolution, aren't set up for that. This is likely because big, blank, featureless things rarely killed us. Or, put another way, our current modern architecture simply hasn't been around long enough to impact behaviors [sic] and a central nervous system that's developed over millennia to ensure the species' survival in the wild. From the brain's visual perspective, blank elevations might as well not be there. (Sussman \& Ward, 2017)

In storytelling, sometimes sameness is found simply in the sameness of typology, especially true for iconic high-rise buildings. The accompanying architectural gymnastics often become predictable and boring (Not Over till Fat Lady Sings, 2018). Often news media reporting exaggerate or confuse visual significance (Owen Hatherley, 2018). And often the story itself becomes the novelty (Paris' Utopian Village, 2018).

The blankness referred to by Sussman et. al contributes to the creeping phenomenon of 'sameness' (Chakrabarti, 2018; Eck, 2018) and needs to be tempered by building sustainable places for people (Hollander, Sussman, \& Carr, 2018; Hollander \& Foster, 2016; Sussman \& Hollander, 2018). We see how buildings start to look back at us (Neglected Utopia, 2016) in all manner of ways: "What Makes Paris Look like Paris?" (Doersch, Singh, Gupta, 
Sivic, \& Efros, 2014) reveals the ultimate irony of technological progress.

Song 5

The fifth song is a song about being completely lost in disfigured space.

Said, well where do you kids live?

Well sir, if you only knew

What the answer is worth

Been searching every corner

Of the earth

(Sprawl I (Flatland), Arcade Fire, 2019).

The cause of this phenomenon of 'sameness' evidently now offers itself up as the solution. The contradiction in all this is in relying on algorithms run through Google Street View to try and identify unique features that we have for decades been trying to destroy.

The opposite may also be true: when over-complication is just as bad for us as blankness or blandness. Spline modellers and big data computation produce disturbingly complicated objects, exemplified by the Michael Hansmeyer and Benjamin Dillenburger in Digital Grotesque Grotto (in Carpo, 2014).

Interiority then can exist by way of songs. Through "unconscious brain activity [which] directs our conscious behaviour" (Sussman \& Chen, 2017). Peterson likens the fact that as social constructs, we interact in a give-take environment with other people who want something from us while we want something from them. The Piagetian games that follow may be true also for the games we play with our built environment. We give form to architecture, music, art, or artefact. These objects (through their function) desire interaction from us. What do we want from them? It can be argued that we want value from them. We want these objects to enrich our lives through meaning. If these objects are alienating, then we are forced to exit (the game) or else we confront the causes of alienation (Peterson, 2017a).

\section{Markers of Interiority: Inside-Out}

Evidence of a failure of a transformation to the meaning beyond the parts is found everywhere in design these days. There are many examples of how attempts to improve quality of life have led to the reverse effect: of alienation in life (Wilson, 2018). A sentiment 
echoed by Dieter Rams "the most influential designer of the last century" (Wilson, 2018):

I always strove for things to be sustainable ... I'm bothered by the arbitrariness and the thoughtlessness with which many things are produced and brought to the market... Unnecessary, false, dishonest products... (Hustwit, 2015)

It is often difficult to understand exactly what is changing in our urban. Perhaps it is simply an over-reliance on contrived design. Which is why this paper has proposed switching the combination of urban indicators up in the manner it has; by exploring the relationship between three very different urban constructs around the concept of interiority.

There are three conditions of interiority discussed in this paper: Buildings, Faces, and Songs of Alienation. We have discussed these conditions in two ways: in epistemically objective terms and as ontologically subjective constructs (Searle, 2016).

The first condition, buildings, represent markers of space in an epistemically objective sense. Here, interior space in buildings provides the meaning for the building in a physical sense. Buildings have an inside and an outside. They delineate internal from external. Buildings can alienate through their facades. Concentrations of buildings, especially of tall buildings, have a physical presence and can disorient. Buildings no longer rely on hard infrastructure to service their interiors.

But buildings are also markers of interiority in an ontologically subjective sense. Here we can think of interiority in the analogy between how we experience as human beings and how this experience helps us intuitively understand the interiority of spaces in buildings. Buildings are not only markers between inside and outside in a physical sense, but can be differentiated (lower case vs capitalised) where capitalised terms represent ontological constructs of an abstraction between the 'Inside' and 'Outside' of our minds or subconscious world. Both physical and abstract representations can alienate and when both simultaneously do, then the sense of alienation, again, is complete because there is no prospect of taking refuge. Buildings can take the form of mental forests or fortresses; representing disorientating and disconcerting ambiguity, or prisons of the mind. The software connecting people inside buildings can compound and convert this form into another: digital forests. 
The second condition, faces, can alienate in an epistemically objective way. But in ontologically subjective terms, faces produce deeper meaning. Meaning transcends understanding through facial expression. Faces are a powerful influencer of meaning even if we do not fully understand how this happens.

The third and last condition, songs of alienation, can help us understand alienation in an epistemically objective sense. This condition can be restorative and healing, can trigger warnings of alienation, and can help bind the social. In an ontologically subjective sense, songs are perfect abstractions of our lives. They are engaging influencers of meaning and represent a powerful method to understand alienation. Songs produce forces that bind left and right hemispheres of our brain; linking rational thought with subconscious thought. Buildings, faces, and songs of alienation are markers of interiority, of the inside-out process through which mind and body can be projected beyond the facade; and ironically back into the spaces contained in the buildings we occupy.

\section{Virtual Markers}

The role of technology is also important because changes in technology help mediate the process linking the meaning inside with the meaning out there. The digital city is already a reality, and every city has some form of digital interior growing that highlights the differences between the real city and virtual city (Rabari \& Storper, 2015). This is compounded by an "aesthetics of uncertainty" (Columbia GSAPP, 2018a, 1:26:42) where: "It is no longer a question of a false representation of reality (ideology), but of concealing the fact that the real is no longer real" (Baudrillard, 1983, p. 25). Trevor Paglen in "Monsters in the Smart City" discusses concepts such as "invisible images ... explosion of visuality" (Columbia GSAPP, 2018b, $0: 07: 27)$, that surpasses the twentieth century rise of mass media and is "characterised by computer vision and ubiquitous sensing, by artificial intelligence, and by infrastructures that are increasingly behaving in seemingly autonomous ways" (Columbia GSAPP, 2018b, $0: 07: 50)$. This phenomenon is "very different from the visuality of the past, first and foremost because it is largely invisible" (Columbia GSAPP, 2018b, 0:08:06).

Technologies that draw or bring places together like phone systems and the internet (Diemer, Currie, De Gruyter, \& Hopkins, 2018) fill the space between places. This compression of space has become even more significant with instant communication and smart city technology (Dixon, Farrelly, \& Pink, 2015). "What Jürgen Habermas so famously defined as the 'public sphere"' (Foer, 2018) has become as 
important as the buildings themselves, not just visually but in terms of visual perception: reflecting a liberty of conscience advocated by Milton (Foer, 2018). These technologies like Google, Facebook, Twitter, and Amazon appear to have the upper hand: "It took centuries for the public sphere to develop-and the technology companies have eviscerated it in a flash ... [as] they weaponize us against ourselves" (Foer, 2018). Today's personal space is not limited by physical location (Carta, 2018; Your Personal Space, 2018); but data is driven towards the inevitable; that "the guy who has the most data, wins" (Google's Road Map, 2013).

Interior space is being reimagined physically. A "laptop computer accessing a wireless network transduces the café, the train station, the park bench, and so on into a work space for that person" (Kitchin \& Dodge, 2011, p. 17). "The check-in area at the airport does not facilitate travel; the store does not operate as a store. Here, "software quite literally conditions ... existence" (Thrift \& French, in Kitchin \& Dodge, 2011, p. 18). The environment is constantly changing and reshaping in the form of "hyper-real geographies... characterised by surface, a 'packaging' which hides the workings of the technology and economy... [lacking] depth - for the consumer - and are virtual in subsisting at the level of an image, theme or gesture" (Rodaway, 2011, p. 178).

\section{Mending the Connectivity}

We have looked at an unlikely combination of three containers of meaning: buildings, faces, and songs. Songs reflect conditions of alienation; of that which is no longer recognisable. Latent or lost meaning can be restored by reversing the connectivity; from songs back to faces, and back again to buildings. Because faces represent what is contained in the minds of people. Faces look both ways: inwards or outwards. We often look for faces in buildings because we want to understand our inanimate objects. We want to understand what is inside, 'in the mind of the building.'

Visual perception has traditionally been implicit in our methods of communication. Historically we mapped out our hidden world over telephone party lines. A shared network of eavesdropping and gossip, itself a form of visual sustenance. Perception was meaning. We can conclude with a final song that has the potential to provide clues to a map that can be used to find our way back from conditions of alienation. For example, we once visualised images as we acted out the process of connecting across telephone cables spanning hardwood poles crisscrossing an entire country. In Wichita Lineman (Savage, 2017), storytelling and music convey a powerful simple 
message: giving visual expression to what people could not see. They saw with their ears and heard with their eyes.

I hear you singing in the wire, I can hear you through the whine And the Wichita Lineman is still on the line I know I need a small vacation but it don't look like rain And if it snows that stretch down south won't ever stand the strain And I need you more than want you, and I want you for all time (Wichita Lineman, Glen Campbell, 2019).

While telephone or telegraph poles were yesterday's connectors, today's connectivity is instant. It may be true that what we cannot see is more meaningful than being able to access almost anything anytime, anywhere. The protection offered by framed views (Cullen, 1995; Collins \& Sitte, 2006) or dream states (Jung, Franz, \& Freeman, 1964 ) is rapidly being dismantled by technology. It may be costly, because seeing everything may mean seeing nothing.

\section{Minding the Connectivity}

Interior space should be about more than the sum of the elements that contain it. Visual meaning of interior space speaks not only to the design and use of building interiors but more importantly, to associated experiences. The associations are drawn from our own internal system; both physical and subconscious. This deeper meaning, of associations around the concept of interiority, is a human condition that is intuitively understood.

Because people ultimately produce the meaning in their surroundings, songs are used to transact with the unknown. Songs are a form of storytelling that expresses conditions of alienation. We sing songs about faces and objects with faces. Songs are a form of mediation between animate and inanimate objects. Songs help us pay attention and help us to see things and events in our world more clearly.

This paper has introduced and discussed three different constructs: buildings, faces and songs of alienation. While buildings and faces can create conditions of alienation, the construct of a song regulates the other two. Songs are interior to us. They regulate how we feel about interiority: in both ourselves and in our buildings. Because, just like interior space should do, songs contain the meaning. 


\section{References}

Aranda, J., Wood, B. K., \& Vidokle, A. (Eds.). (2015). The internet does not exist. Berlin: Sternberg Press.

Arcade Fire Lyrics: "Modern Man" (2019). Retrieved from https:// www.azlyrics.com/lyrics/arcadefire/modernman.html

Arcade Fire Lyrics:"My Body Is A Cage"(2019). Retrieved from https:// www.azlyrics.com/lyrics/arcadefire/mybodyisacage.html

Arcade Fire Lyrics:"Sprawl I (Flatland)"(2019). Retrieved from https:// www.azlyrics.com/lyrics/arcadefire/sprawliflatland.html

Arcade Fire Lyrics: "Suburban War" (2019). Retrieved from https:// www.azlyrics.com/lyrics/arcadefire/suburbanwar.html

Ballantyne, A. (2007). Deleuze and Guattari for architects. London; New York: Routledge.

Baudrillard, J. (1983). Simulations. New York: Semiotext(e).

Berleant, A. (1997). Living in the landscape: Toward an aesthetics of environment. Lawrence: University Press of Kansas.

Beyond good and evil, by Friedrich Nietzsche. (2009, December 7). Retrieved from https://www.gutenberg.org/ files/4363/4363-h/4363-h.htm

Brussat, D. (2017, November 30). Our eyes poke back at mods. Retrieved from https://architecturehereandthere. com/2017/11/29/eye-tracking-sussman-architecture/

Brussat, D. (2018, December 28). New blog page on 'Dystopia'. Retrieved from https://architecturehereandthere. com/2018/12/28/new-blog-page-on-dystopia/

Carey, J.T. (1969). Changing courtship patterns in the popular song. American Journal of Sociology, 74(6), 720-731. https://doi. org/10.1086/224722

Carpo, M. (2014, February). Breaking the curve: Big data and design. Retrieved from https://www.artforum.com/print/201402/ breaking-the-curve-big-data-and-design-45013

Carta, S. (2018). Digital personal space: From the plaza to the global canopy. Journal of Urban Cultural Studies, 5(1), 91105. https://doi.org/10.1386/jucs.5.1.91_1 
Chakrabarti, V. (2018). How we can design timeless cities for our collective future. Retrieved from https://www.ted. com/talks/vishaan_chakrabarti_how_we_can_design_ timeless_cities_for_our_collective_future

Collins, G. R., \& Sitte, C. (2006). Camillo Sitte: The birth of modern city planning. Mineola, NY: Dover.

Columbia GSAPP. (2018a). Ways of knowing cities [Video file]. Retrieved from https://www.youtube.com/ watch?v=VPnn2z9tbls

Columbia GSAPP. (2018b). Ways of knowing cities Panel 7 [Video file]. Retrieved from https://www.youtube.com/ watch? $v=$ L4iwcgHciow

Cullen, G. (1995). The concise townscape. Oxford; Boston: Butterworth-Heinemann.

Diemer, M. J., Currie, G., De Gruyter, C., \& Hopkins, I. (2018). Filling the space between trams and place: Adapting the 'Movement \& Place' framework to Melbourne's tram network. Journal of Transport Geography, 70, 215-227. https://doi.org/10.1016/j.jtrangeo.2018.06.010

Dixon, T., Farrelly, L., \& Pain, K. (2015). A smart and sustainable urban future. Estate Gazettes, 100-102. Retrieved from http://www.estategazettes.com

Doersch, C., Singh, S., Gupta, A., Sivic, J., \& Efros, A. (2014). What makes Paris look like Paris? ACM Transactions on Graphics, $31(4)$

Eck, J. (2018, July 18). Cross-country redux: An architect's inspiringand dispiriting-drive across America. Retrieved from http://commonedge.org/an-architects-inspiring-anddispiriting-drive-across-america/

Farias, I., \& Bender, T. (Eds.). (2010). Urban assemblages: How actornetwork theory changes urban studies. London; New York: Routledge.

Foer, F. (2018, July 6). The death of the public square. Retrieved from https://www.theatlantic.com/ technology/archive/2018/07/the-death-of-the-publicsquare/564506/

Glen Campbell Lyrics: "Wichita Lineman" (2019). Retrieved 
from https://www.azlyrics.com/lyrics/glencampbell/ wichitalineman.html

Google's Road Map to Global Domination (2013, December 11). The New York Times. Retrieved from https://www.nytimes. com/2013/12/15/magazine/googles-plan-for-globaldomination-dont-ask-why-ask-where.html

Hollander, J. B., Sussman, A., \& Carr, H. C. (2018). Seeing the 'unseen' in Devens. Retrieved from https://www. cnu.org/sites/default/files/Seeing\%20the\%20 \% E 2\% $80 \% 98$ Un see n \% E $2 \% 80 \% 99 \% 20$ in \% 20 Devens\%2C\%20MA.pdf

Hollander, J., \& Foster, V. (2016). Brain responses to architecture and planning: A preliminary neuro-assessment of the pedestrian experience in Boston, Massachusetts. Architectural Science Review, 59(6), 474-481. https://doi.or g/10.1080/00038628.2016.1221499

Hustwit, G. (2015, March 18). Dieter Rams: If I could do it again, "I would not want to be a designer." Retrieved from https:// www.fastcompany.com/3043815/dieter-rams-if-i-coulddo-it-again-i-would-not-want-to-be-a-designer

I run "facial recognition" on buildings to unlock architectural secret. (2018, April 20). Retrieved from https://www. fastcompany.com/90168809/i-run-facial-recognition-onbuildings-to-unlock-architectural-secrets

Jung, C. G. (2015). Man and his symbols by Carl G Jung 6 [Video file]. Retrieved from https://www.youtube.com/ watch?v=ozVSJCsa7Co

Jung, C. G., Franz, M.-L., \& Freeman, J. (1964). Man and his symbols. New York: Anchor Books.

Kitchin, R., \& Dodge, M. (2011). Code/space: Software and everyday life. Cambridge, Mass.: MIT Press.

Koch, C. (2013). Lecture 11: Visual Attention and Consciousness [Video file]. Retrieved from https://www.youtube.com/ watch?v=pnfudjQwjS8\&

Leach, N. (Ed.). (1997). Rethinking architecture: A reader in cultural theory. New York: Routledge.

Lefebvre, H., \& Nicholson-Smith, D. (2011). The production of space. 
Malden, Mass.: Blackwell.

Movers and shakers: New digital executive roles for Cameron Brill and Richard Kay (2018, February 19). Retrieved from https://www.cio.co.nz/article/633546/why-data-drivencustomer-centric-mentality-future-everything/

Neglected utopia: Photographer explores the forgotten modernist estates of Paris. (2016, February 16). Retrieved from http://www.creativeboom.com/photography/neglectedutopia-photographer-explores-the-forgotten-modernistestates-of-paris/

Not over till fat lady sings (2018, May 16). Retrieved from https:// architecturehereandthere.com/2018/05/16/fane-towerrejected-by-cpc/

Otty, L. (2005). The No Man Show: Technology and the extension of presence in the work of Andy Warhol. ESharp, 5.

Owen Hatherley: 'What is happening at Sewoon Sangga is extraordinary' (2018, January 4). Retrieved from https:// www.dezeen.com/2018/01/04/owen-hatherleysewoon-sangga-seoul-extraordinary-revamp-brutalistmegastructure/

Paris' Utopian village of concrete cabbage (2018). Retrieved from http://themindcircle.com/paris-utopian-village-concretecabbage/

Peterson, J. B. (2017a). 2017 Personality 02/03: Historical \& Mythological Context [Video file]. Retrieved from https:// www.youtube.com/watch?v=HbAZ6cFxCeY

Peterson, J. B. (2017b). 2017 Personality 04/05: Heroic and Shamanic Initiations [Video file]. Retrieved from https:// www.youtube.com/watch?v=wLc_MC7NQek

Peterson, J. B. (2017c). 2017 Personality 06: Jean Piaget \& Constructivism [Video file]. Retrieved from https://www. youtube.com/watch?v=BQ4VSRg4e8w

Polanyi, M., \& Grene, M. (1969). Knowing and being. London: Routledge and Kegan Paul.

Rabari, C., \& Storper, M. (2015). The digital skin of cities: Urban theory and research in the age of the sensored and metered city, ubiquitous computing and big data. Cambridge Journal 
of Regions, Economy and Society, 8(1), 27-42. https://doi. org/10.1093/cjres/rsu021

Rodaway, P. (2011). Sensuous geographies: Body, sense, and place. London: Routledge.

Salingaros, N. A. (1999). Urban space and its information field. Journal of Urban Design, 4(1), 29-49. https://doi. org/10.1080/13574809908724437

Salingaros, N. A., \& Mehaffy, M. W. (2006). A theory of architecture. Solingen: Umbau-Verl.

Savage, M. (2017, August 9). Wichita Lineman: The unfinished classic. BBC News. Retrieved from https://www.bbc.com/ news/entertainment-arts-40861326

Searle, J. (2016). The problem of perception \& intentionality [Video file]. Retrieved from https://www.youtube.com/ watch?v=If_4t0_HUx8

Sharr, A. (2007). Heidegger for architects. London; New York: Routledge.

Stafford, B. M. (2014). Selective attention: Neuroscience and the art museum [Video file] Retrieved from https://www. youtube.com/watch?v=AvoGEScg0m4\&feature=youtu.be

Sussman, A., \& Chen, K. (2017, August 22). The mental disorders that gave us modern architecture. Retrieved from http:// commonedge.org/the-mental-disorders-that-gave-usmodern-architecture/

Sussman, A., \& Hollander, J. (2018, July 19). Three fundamental errors in architectural thinking and how to fix them. Retrieved from https://www.cnu.org/publicsquare/2018/07/19/ three-fundamental-errors-architectural-thinking-andhow-fix-them

Sussman, A., \& Ward, J. M. (2016, June). Planning for the subconscious. Retrieved from https://www.planning.org/ planning/2016/jun/subconscious/

Sussman, A., \& Ward, J. M. (2017, November 27). Game-changing eye-tracking studies reveal how we actually see architecture. Retrieved from http://commonedge.org/ game-changing-eye-tracking-studies-reveal-how-weactually-see-architecture/ 
The neuroscience of architecture: The good, the bad-and the beautiful-Historic properties and traditional architecture (2018, February 19). Retrieved from https://www. traditionalbuilding.com/opinions/the-neuroscience-ofarchitecture

The Troggs Lyrics:"Wild Thing" (2019). Retrieved from https://www. azlyrics.com/lyrics/troggs/wildthing.html

Twenty years later, everything is The Truman Show (2018, June 5). Vanity Fair. Retrieved from https://www.vanityfair. com/hollywood/2018/06/truman-show-anniversary-jimcarrey-peter-weir-laura-linney

Wilson, M. (2018, February 26). A mesmerizing first look at the Dieter Rams documentary. Retrieved from https://www. fastcompany.com/90161817/a-mesmerizing-first-look-atthe-dieter-rams-documentary

Wilson, M. (2018, October 8). Dieter Rams wants Silicon Valley to stop. Retrieved from https://www.fastcompany. com/90246965/dieter-rams-wants-silicon-valley-to-stop

Your city is watching you. (2018, January 17). Retrieved from https://www.curbed.com/2018/1/17/16897222/machinelearning-urban-planning-sidewalk-labs

Your personal space is no longer physical-It's a global network of data. (2018, June 1). Retrieved from https:// theconversation.com/your-personal-space-is-no-longerphysical-its-a-global-network-of-data-97140 